\title{
Genetic variation in eight Chinese cattle breeds based on the analysis of microsatellite markers
}

\author{
Weibin Sun ${ }^{1}$, Hong Chen ${ }^{1,2 *}$, Chuzhao LeI ${ }^{1}$, Xueqin $\mathrm{LEI}^{3}$, \\ Yinghan $\mathrm{ZHANG}^{1}$ \\ ${ }^{1}$ College of Animal Science and Technology, Northwest A\&F University, Shaanxi Key \\ Laboratory of Molecular Biology for Agriculture, Yangling, Shaanxi 712100, China \\ ${ }^{2}$ Institute of Cellular and Molecular Biology, Xuzhou Normal University, Xuzhou, \\ Jiangsu 221116, China \\ ${ }^{3}$ Henan Sci-tech University, Luoyang, Henan 471000, China
}

(Received 16 December 2007; accepted 16 May 2008)

\begin{abstract}
Genetic variability and genetic relationships were investigated among eight Chinese cattle breeds using 12 microsatellite markers. Three hundred and fifty-two alleles were detected and the average number of alleles per locus ranged from $8.33 \pm 1.67$ in the Jiaxian breed to $21.33 \pm 5.60$ in the Qinchuan breed with a mean value of 13.91. The total number of alleles per microsatellite ranged from 21 (INRA005, HEL1) to 40 (HEL13), with a mean of 29.33 per locus. The fixation indices at the 12 loci in the eight breeds were very low with a mean of 0.006 . A principal components analysis and the construction of a neighborjoining tree showed that these eight Chinese cattle breeds cluster into three groups i.e. the Yanbian and Chinese Holstein, the Nanyang and Jiaxian, and the four remaining breeds. This clustering agrees with the origin and geographical distributions of these Chinese breeds.
\end{abstract}

Chinese cattle breed / microsatellite DNA / genetic variability / genetic relationship

\section{INTRODUCTION}

Since the 1980s, the Chinese beef industry has expanded considerably and this progress has been accompanied by the introduction of several foreign specialized beef breeds, especially from Europe. European breeds are often used as sire lines for crossbreeding with Chinese indigenous cattle breeds. Such breeding schemes have contributed in improving individual weight gain and beef carcass weight of Chinese breeds [27], which only account for two-thirds of the world average level and about one half of that in developed countries, such as Canada, Australia, and USA. However, such crossbreeding with foreign

${ }^{*}$ Corresponding author: chenhong1212@263.net 
breeds also results in consistent and rapid loss of genetic diversity by dilution of the autochthonous genetic makeup.

The existence of genetic polymorphism or diversity in a population is the basis of genetic improvement by selection and needs to be accurately estimated [23]. In the past decades, animal genetic diversity has been assessed according to various criteria including phenotypic, biochemical, and molecular parameters. With the development of molecular biology techniques, nucleotide variations in DNA sequences can be detected directly such as microsatellite markers identified in all eukaryotic species investigated so far $[3,18]$. Microsatellite markers have become the mainstay of genetic linkage mapping and quantitative trait loci identification for economic traits and they have also been used to address questions concerning the genetic diversity and the genetic relationships in species such as cattle [11]. However, in cattle, most of these studies have focused on European breeds and little information is available on the genetic diversity of Chinese indigenous cattle breeds. The purpose of the present study was to evaluate the genetic diversity of eight cattle breeds in China based on microsatellite markers and to estimate the genetic relationships among these eight breeds.

\section{MATERIALS AND METHODS}

\subsection{Sample collection for DNA analysis}

Three hundred and thirty animals from eight Chinese indigenous cattle breeds i.e. Qinchuan (QC, 120), Nanyang (NY, 30), Jiaxian (JX, 30), Luxi (LX, 30), Bohai (BH, 30), Jinnan (JN, 30), Chinese Holstein $(\mathrm{CH}, 30)$, and Yanbian (YB, 30) were analyzed. Blood and tissue samples were collected from various geographical locations (Fig. 1), because these breeds are distributed over five Chinese provinces (Jilin, Shandong, Shaanxi, Shanxi, and Henan). Economically, the most important cattle breeds in China are the Qinchuan, Jinnan, Nanyang, Luxi, and Yanbian breeds since they represent $90 \%$ of the retail beef market share in China.

\subsection{DNA extraction and PCR amplification}

DNA was extracted using standard SDS lysis, proteinase K digestion, phenol/ chloroform extraction, and ethanol precipitation [19]. DNA samples were resuspended in TE buffer $\left(10 \mathrm{mmol} \cdot \mathrm{L}^{-1}\right.$ Tris- $\mathrm{HCl}, 1 \mathrm{mmol} \cdot \mathrm{L}^{-1}$ EDTA, $\left.\mathrm{pH}=8\right)$ and stored at $-20{ }^{\circ} \mathrm{C}$.

Twelve bovine microsatellite markers were selected from the CaDBase database on Genetic Diversity in Cattle (http://www.projects.roslin.ac.uk/cdiv/ markers.html) and the USDA Cattle Genome Mapping Project (http:// www.marc.usda.gov/genome/cattle/cattle.html). 


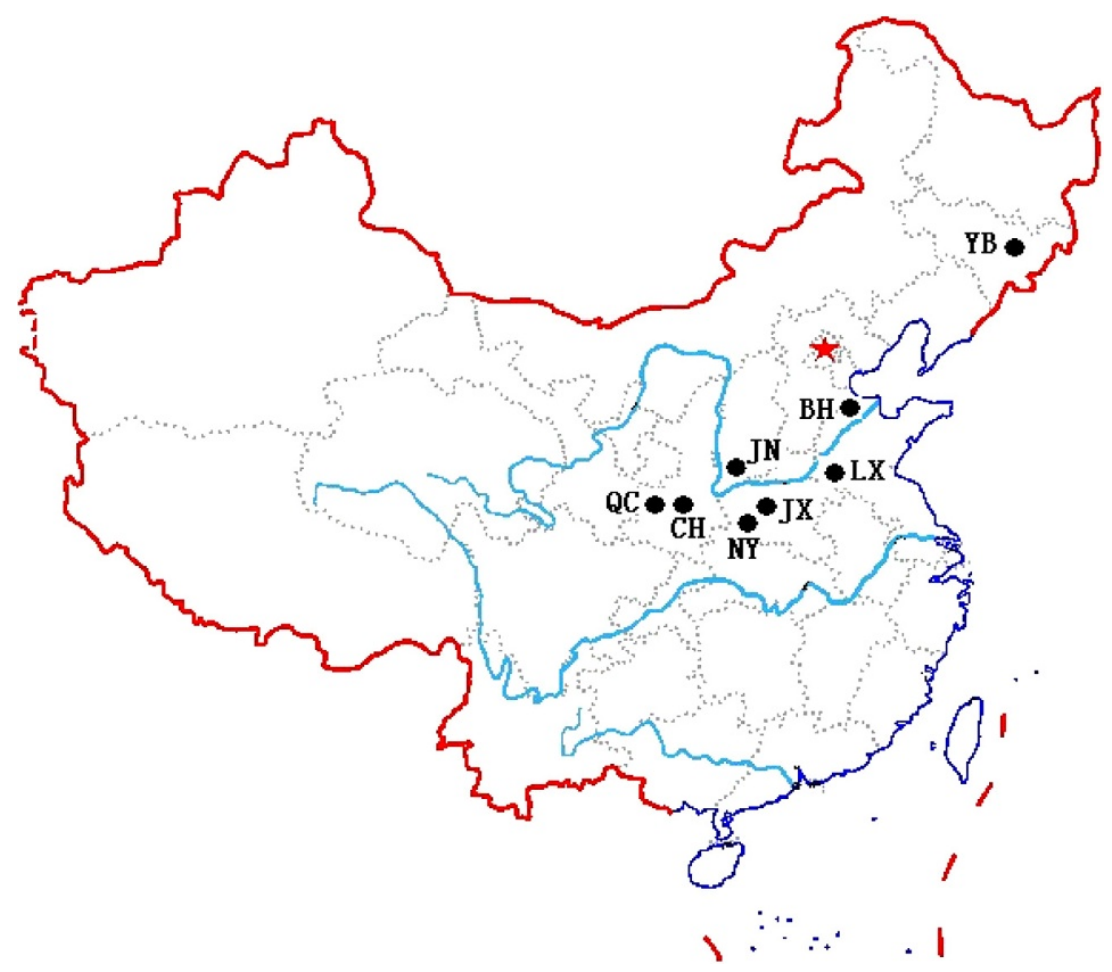

Figure 1. Geographic localizations of the eight cattle breeds analyzed in this study. YB: Yanbian, BH: Bohai, JN: Jinnan, LX: Luxi, QC: Qinchuan, CH: Chinese Holstein, JX: Jiaxian, NY: Nanyang.

Polymerase chain reactions (PCR) were performed in $12 \mu \mathrm{L}$ reaction mixtures using the Biometra TGradient Thermal Cycler (Germany). Each reaction mixture contained $1.0 \mu \mathrm{L}$ (final concentration $0.5 \mathrm{U} \cdot \mu \mathrm{L}^{-1}$ ) of $\mathrm{Ex} \mathrm{Taq}{ }^{\mathrm{TM}}$, DNA polymerase (TaKaRa Biotechnology Co., Ltd., Japan), $1.2 \mu \mathrm{L}$ of $10 \mathrm{X}$ PCR buffer, $1.5 \mu \mathrm{L}$ of $\mathrm{MgCl}_{2}\left(25 \mathrm{mmol} \cdot \mathrm{L}^{-1}\right), 0.75 \mu \mathrm{L}$ of dNTPs $\left(2.5 \mathrm{mmol} \cdot \mathrm{L}^{-1}\right), 1.0 \mu \mathrm{L}$ of primers $\left(10 \mu \mathrm{mol} \cdot \mathrm{L}^{-1}\right), 2.0 \mu \mathrm{L}$ of template DNA $\left(50 \mathrm{ng} \cdot \mu \mathrm{L}^{-1}\right.$ ), and $4.55 \mu \mathrm{L}$ of sterile $\mathrm{H}_{2} \mathrm{O}$. The following PCR conditions were used: initial denaturation at $95{ }^{\circ} \mathrm{C}$ for $2 \mathrm{~min}$, followed by 35 cycles of $30 \mathrm{~s}$ at $94{ }^{\circ} \mathrm{C}$ (denaturation), $30 \mathrm{~s}$ at the optimal temperature for each primer pair (annealing), and $45 \mathrm{~s}$ at $72{ }^{\circ} \mathrm{C}$ (elongation), and a final extension step at $72{ }^{\circ} \mathrm{C}$ for $10 \mathrm{~min}$. The reaction mixtures were stored at $4{ }^{\circ} \mathrm{C}$. After the PCR amplification, 3-4 $\mu \mathrm{L}$ of PCR product was loaded onto an $8 \%$ polyacrylamide non-denaturing gel with $\mathrm{pBR} 322 \mathrm{DNA} / \mathrm{MspI}$ as the molecular size marker. After electrophoresis (3-4 h at $120 \mathrm{~V})$, the gels were stained with silver 
nitrate and the fragment sizes were read using the Kodak Digital Science ID Image Analysis System.

\subsection{Data analysis}

First, genotyping data were processed with the Excel Microsatellite Toolkit [14] (http://www.animalgenomics.ucd.ie/sdepark/ms-toolkit). Then, we used the $F$-stat software (2.9.3.2) to determine the genetic variation within and between breeds, the number of alleles, and the heterozygosities, and the Wright $F$-statistics [25] and the DISPAN software [13] to calculate genetic distances $\left(D_{\mathrm{A}}\right)$ [12]. A principal components analysis (PCA) of allelic frequencies was carried out according to the procedures described by Cavalli-Sforza et al. [4] using SPSS (11.5.0). Phylogenetic analyses were conducted with the MEGA4 software package [22] using the neighbor-joining method [18].

\section{RESULTS}

\subsection{Genetic variability}

Overall, 352 alleles were detected for the 12 microsatellite loci in 350 animals from the eight Chinese cattle breeds studied with the number of alleles per locus ranging from 21 (INRA005, HEL1) to 40 (HEL13) and with a mean of 29.33. When analyzing the breeds separately, the number of alleles per locus ranged from $8.33 \pm 1.67$ (Jiaxian breed) to $21.33 \pm 5.60$ (Qinchuan breed) with a mean of 13.91 (Tabs. I and II). Overall, 61 breed-private alleles were found in the eight breeds, 25 were identified in the Qinchuan breed, while only one was detected in each of the Jiaxian and Jinnan breeds. The mean number of alleles per locus in the Qinchuan breed was significantly larger than that in the other breeds. Except for microsatellites BM1824, TGLA227, and BM315 in the Nanyang breed, TGLA227, HEL5, HEL9, and BM315 in Jinnan, BM2113 and HEL13 in Chinese Holstein, TGLA227 in Luxi, INRA005 in Jiaxian, and HEL9 and INRA005 in Yanbian, which were in Hardy-Weinberg equilibrium $(P>0.05)$, all other loci departed from the Hardy-Weinberg equilibrium $(P<0.01$ or $P<0.05$, data are not shown here).

For the 12 microsatellite loci, observed heterozygosities and expected heterozygosities ranged from 0.78 (INRA005) to 0.95 (BM1824) and from 0.86 (TGLA126, INRA005) to 0.93 (HEL13), respectively. The values of observed heterozygosity and expected heterozygosity at loci BM1824, BM2113, TGLA126, and HEL1 differed significantly $(P<0.01$ or $P<0.05)$. Observed heterozygosities and expected heterozygosities across the eight breeds varied 
Table I. Number of microsatellite alleles observed $(N)$, range of allele sizes, observed heterozygosities $\left(H_{\mathrm{O}}\right)$, expected heterozygosities $\left(H_{\mathrm{S}}\right), P I C$, allelic richness, and fixation indices at each locus.

\begin{tabular}{|c|c|c|c|c|c|c|c|c|c|}
\hline \multirow[t]{2}{*}{ Locus } & \multirow{2}{*}{$\begin{array}{l}\text { Number of } \\
\text { alleles }(N)\end{array}$} & \multirow{2}{*}{$\begin{array}{c}\text { Sizes of } \\
\text { alleles (bp) }\end{array}$} & \multirow[t]{2}{*}{$H_{\mathrm{O}}$} & \multirow[t]{2}{*}{$H_{\mathrm{S}}$} & \multirow[t]{2}{*}{ PIC } & \multirow{2}{*}{$\begin{array}{c}\text { Allelic } \\
\text { richness }\end{array}$} & \multicolumn{3}{|c|}{ Fixation indices } \\
\hline & & & & & & & $F_{\text {IS }}$ & $F_{\text {IT }}$ & $F_{\mathrm{ST}}$ \\
\hline BM1824 & 28 & $171-247$ & $0.95^{\mathrm{a}}$ & $0.89^{b}$ & 0.87 & 7.40 & -0.06 & -0.02 & 0.04 \\
\hline$B M 2113$ & 31 & $124-170$ & $0.98^{\mathrm{A}}$ & $0.91^{\mathrm{B}}$ & 0.88 & 7.87 & -0.07 & -0.04 & 0.03 \\
\hline CSSM66 & 36 & $175-247$ & 0.91 & 0.90 & 0.86 & 7.50 & -0.01 & 0.03 & 0.03 \\
\hline ETH152 & 28 & $179-235$ & 0.85 & 0.90 & 0.86 & 7.81 & $0.06^{* *}$ & 0.10 & 0.04 \\
\hline TGLA126 & 22 & $113-149$ & $0.92^{\mathrm{a}}$ & $0.86^{\mathrm{b}}$ & 0.86 & 6.71 & -0.06 & -0.02 & 0.04 \\
\hline TGLA227 & 31 & $67-125$ & 0.94 & 0.90 & 0.86 & 7.67 & $-0.05^{*}$ & -0.002 & 0.05 \\
\hline INRA005 & 21 & $135-177$ & 0.78 & 0.86 & 0.82 & 6.17 & 0.10 & 0.14 & 0.04 \\
\hline HEL1 & 21 & $101-145$ & $0.94^{\mathrm{A}}$ & $0.89^{\mathrm{B}}$ & 0.85 & 6.83 & -0.06 & -0.03 & 0.02 \\
\hline HEL5 & 31 & $119-205$ & 0.73 & 0.91 & 0.87 & 7.70 & 0.20 & 0.23 & 0.04 \\
\hline HEL9 & 33 & $141-193$ & 0.94 & 0.91 & 0.88 & 7.88 & -0.03 & 0.00 & 0.03 \\
\hline HEL13 & 40 & $142-228$ & 0.87 & 0.93 & 0.89 & 8.27 & $0.07^{* *}$ & 0.09 & 0.02 \\
\hline BM315 & 30 & $102-174$ & 0.91 & 0.92 & 0.88 & 8.08 & $0.01^{* *}$ & 0.04 & 0.03 \\
\hline Total & 352 & - & - & - & - & - & - & - & - \\
\hline Mean & 29.33 & - & 0.89 & 0.90 & 0.87 & - & 0.008 & 0.04 & 0.04 \\
\hline
\end{tabular}

Notes: $H_{\mathrm{O}}, H_{\mathrm{S}}$ marked with different letters were significantly different to each other $\left({ }^{\mathrm{a}, \mathrm{b}}: P<0.05,{ }^{\mathrm{A}, \mathrm{B}}: P<0.01\right) ; F_{\mathrm{IS}}$ values marked with ${ }^{* *}$ or ${ }^{*}$ were significantly different from zero $\left({ }^{* *} P<0.01,{ }^{*} P<0.05\right)$. 
Table II. Mean number of alleles per locus (NA), expected and observed heterozygosities $\left(H_{\mathrm{S}}\right.$ and $\left.H_{\mathrm{O}}\right), P I C$, breed-private allele numbers, and $F_{\mathrm{IS}}$ observed from the 12 microsatellites in eight Chinese cattle breeds.

\begin{tabular}{lcccccc}
\hline Breeds & NA & $H_{\mathrm{S}}$ & $H_{\mathrm{O}}$ & PIC & $\begin{array}{c}\text { Private } \\
\text { allele } \\
\text { number }\end{array}$ & $F_{\text {IS }}$ \\
\hline Qinchuan & 21.33 & 0.81 & 0.91 & 0.90 & 25 & $0.09^{* *}$ \\
Nanyang & 13.08 & 0.89 & 0.90 & 0.87 & 14 & 0.01 \\
Jiaxian & 8.33 & 0.87 & 0.86 & 0.80 & 1 & -0.02 \\
Luxi & 14.67 & 0.95 & 0.91 & 0.88 & 5 & -0.05 \\
Bohai & 13.92 & 0.92 & 0.89 & 0.86 & 2 & -0.03 \\
Jinnan & 13.67 & 0.92 & 0.93 & 0.87 & 1 & 0.003 \\
Chinese Holstein & 12.58 & 0.86 & 0.89 & 0.85 & 4 & 0.04 \\
Yanbian & 13.67 & 0.90 & 0.91 & 0.88 & 9 & $0.01^{*}$ \\
Total & - & - & - & - & 61 & - \\
Mean & - & 0.81 & 0.90 & 0.87 & 7.63 & 0.006 \\
\hline
\end{tabular}

Note: $F_{\text {IS }}$ values marked with ${ }^{* *}$ or ${ }^{*}$ were significantly different from zero $\left({ }^{* *} P<0.01\right.$, $\left.{ }^{*} P<0.05\right)$.

from 0.81 (Qinchuan breed) to 0.95 (Luxi breed) and from 0.86 (Jiaxian breed) to 0.93 (Jinnan breed), respectively. $F_{\text {IS }}$ values of the Qinchuan and Yanbian breeds were significantly different from $0(P<0.01$ or $P<0.05)$. Allelic richness (mean number of alleles per locus) in the eight populations ranged from 6.17 (INRA005) to 8.27 (HEL13), with a mean of 7.49. $F_{\text {IS }}$ values at loci ETH152, TGLA227, HEL13, and BM315 differed significantly from 0 $(P<0.01$ or $P<0.05)$. In all the eight breeds, $F_{\text {IS }}$ values were very low, with negative values in Jiaxian, Luxi, and Bohai breeds and positive values in Qinchuan, Nanyang, Jinnan, Chinese Holstein, and Yangbian breeds. The means of $F_{\mathrm{IS}}, F_{\mathrm{IT}}$, and $F_{\mathrm{ST}}$ at the 12 microsatellite loci and in the eight breeds were $0.01,0.04$, and 0.04 , which indicate that $4 \%$ of the genetic variability depends on the breed and $96 \%$ on the individual's genotype. Average polymorphism information content $(P I C)$ values for the 12 loci ranged from 0.82 (INRA005) to 0.89 (HEL13) and all these loci appeared to be highly informative $(P I C>0.5)$ in the eight breeds.

\subsection{Breed relationships and genetic distances}

A PCA was performed for allelic frequencies using the breed as the only factor to summarize breed relationships (Fig. 2). The percentages of variance explained by the first three components were $41.63 \%, 13.98 \%$, and $11.25 \%$, respectively. According to the principal component matrix (not shown here), 


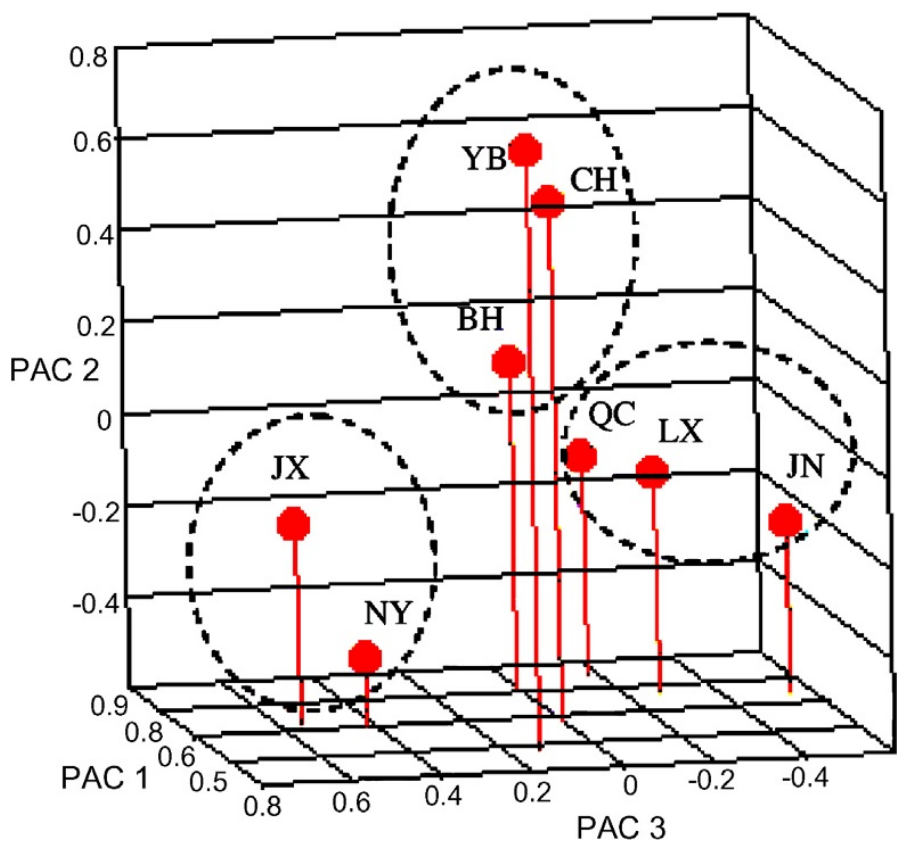

Figure 2. Three-dimensional plot of PAC1, PAC2 vs. PAC3 based on allele frequencies of 12 microsatellite markers in eight breeds. YB: Yanbian $(0.403,0.716$, and 0.136); CH: Chinese Holstein (0.559, 0.538, and 0.010); BH: Bohai (0.747, 0.126, and 0.020); QC: Qinchuan (0.803, -0.116, and -0.166); LX: Luxi (0.694, -0.118 , and -0.269$)$; JN: Jinnan $(0.656,-0.224$, and -0.541$)$; NY: Nanyang $(0.588$, -0.443 , and 0.425$)$; and JX: Jiaxian $(0.629,-0.161$, and 0.554$)$.

the first principal components of the eight breeds were all positive, the second principal components were negative for the Yanbian, Chinese Holstein, and Bohai breeds and positive for the others, the third principal components were positive for the Qinchuan, Luxi, and Jinnan breeds and negative for the others. Thus, these eight cattle breeds can be roughly divided into three groups: Yanbian, Chinese Holstein, and Bohai breeds in one group, Qinchuan, Luxi, and Jinnan breeds in the second group, and Jiaxian and Nanyang breeds in the third group.

Allele frequencies were used to generate the $D_{\mathrm{A}}$ genetic distance for each pair of cattle breeds (Tab. III). The $D_{\text {A }}$ genetic distances ranged from 0.229 (between Bohai and Jiaxian breeds) to 0.56 (between Yanbian and Nanyang breeds). These $D_{\mathrm{A}}$ genetic distances were used to construct a neighbor-joining tree (Fig. 3) revealing the clustering of the eight populations into three groups: (1) Yanbian and Chinese Holstein breeds; (2) Qinchuan, Luxi, and Jinnan breeds; and (3) Nanyang, Jiaxian, and Bohai breeds. 
Table III. $D_{\mathrm{A}}$ genetic distances computed using allele frequencies of the 12 microsatellite makers among eight Chinese cattle breeds.

\begin{tabular}{lllllllll}
\hline Breeds & Qinchuan & Nanyang & Jiaxian & Bohai & Luxi & Jinnan & $\begin{array}{c}\text { Chinese } \\
\text { Holstein }\end{array}$ & Yanbian \\
\hline Qinchuan & 0 & & & & & & & \\
Nanyang & 0.389 & 0 & & & & & & \\
Jiaxian & 0.370 & 0.3841 & 0 & & & & & \\
Bohai & 0.297 & 0.441 & 0.229 & 0 & & & & \\
Luxi & 0.278 & 0.452 & 0.417 & 0.291 & 0 & & & \\
Jinnan & 0.301 & 0.449 & 0.490 & 0.298 & 0.265 & 0 & & \\
Chinese & 0.332 & 0.516 & 0.475 & 0.331 & 0.343 & 0.364 & 0 & \\
Holstein & & & & & & & & \\
Yanbian & 0.402 & 0.558 & 0.547 & 0.369 & 0.392 & 0.459 & 0.381 & 0 \\
\hline
\end{tabular}

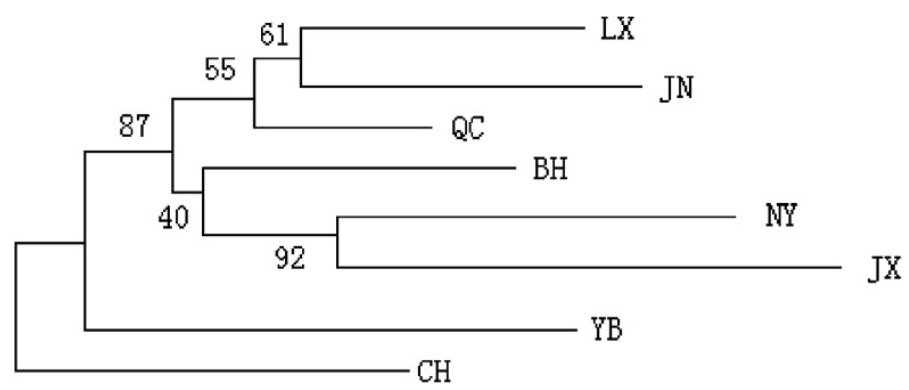

Figure 3. Genetic relationships between eight Chinese cattle breeds. Placements were inferred using the neighbor-joining method. Numbers represent the percentage of times that a node occurred in 1000 bootstrap replicates. YB: Yanbian, BH: Bohai, JN: Jinnan, LX: Luxi, QC: Qinchuan, CH: Chinese Holstein, JX: Jiaxian, NY: Nanyang.

\section{DISCUSSION}

\subsection{Genetic diversity}

Population genetic diversity can be evaluated by the number of alleles per locus, the average number of alleles for all loci, heterozygosity, and PIC value. In this study, 352 alleles were found for the 12 microsatellite loci across the eight Chinese bovine breeds examined. The average number of alleles per locus, considering all eight populations, was 29.33. It has been determined that microsatellite loci used to estimate genetic distances should have at least four alleles in order to reduce the standard errors of distance estimates [1]. Thus, all the microsatellite markers used in this study are suitable for population 
genetic diversity analyses. Sixty-one breed-private alleles were identified over the eight Chinese bovine breeds with 25 present in the Qinchuan breed and only one in each of the Jiaxian and Jinnan breeds. The fact that in this study a higher number of alleles and breed-private alleles were found at each locus in the Qinchuan breed can be explained by its larger population size. The larger a population is, the more alleles with low frequencies can be detected [26].

Takezaki et al. [21] have suggested that for markers to be useful to measure genetic variation, they should have an average heterozygosity higher than 0.3 in the population. Marker heterozygosities in the eight populations of this study range between 0.73 and 0.98 and thus it was considered that they were appropriate.

$P I C$ is an indicator of the degree of informativeness of a marker. According to the criteria of Botstein et al. [2], all 12 microsatellite loci included in this study are highly informative $(P I C>0.5)$ and thus will be useful to evaluate the genetic diversity in Chinese bovine breeds. The mean PIC content in the eight studied populations was between 0.85 and 0.90 , the Chinese Holstein breed showing the lowest value and the Qinchuan breed the highest. The low PIC of Chinese Holstein may be due to the high selection pressure applied in this breed for 100 years [16].

Since the early 19th century, when the concept of a breed grew in currency, many European bovine breeds have become genetically isolated and in most cases their origins can be traced to a small pool of founder individuals. This is also the case for Chinese Holstein cattle, which have experienced a similar breeding practice. Thus, not only the narrow genetic background of this breed but also the inbreeding and the higher selection pressure, have contributed to the loss of genetic variation, which is revealed by reduced allele numbers and lower PIC values [20]. Meanwhile, breeding strategies for Chinese native bovine breeds have changed over time [5], but no extensive breeding program for a specialized selection has been undertaken during a sufficiently long period. Thus, these breeds still possess an abundant genetic polymorphism at most loci, and indeed the 12 microsatellite loci analyzed in the eight breeds, here, are highly polymorphic.

\subsection{Relationships and origin of Chinese bovine breeds}

In Bovine Breeds in China, published in 1986, 28 Chinese native breeds were classified into three groups i.e. humpless, semi-humped, and humped types from the north to the south [16]. The Yanbian breed, present in the north of China, is humpless cattle and has been shown to be genetically close to European breeds based on blood polymorphisms [24] and karyotype analyses [8]. In our study, we found that the Yanbian breed is positioned close to the Chinese Holstein 
breed both by PCA and construction of a phylogenetic tree with $D_{\mathrm{A}}$ distances (Figs. 2 and 3). The Nanyang breed is obviously humped cattle and has a zebu-like Y chromosome [8] and could be phylogenetically close to zebus, but mtDNA sequencing analyses have indicated that the Nanyang breed possesses maternal origins from both Bos taurus and Bos indicus [9]. Qinchuan, Jinnan, Luxi, Bohai, and Jiaxian are semi-hump breeds and they are all distributed in central China and have complex Y chromosomal types [8] and mtDNA haplotypes [9]. It has been shown that these breeds result from crossbreeding between northern breeds (B. taurus) and southern breeds (B. indicus) $[7,10]$ clustered together. In this study, the largest $D_{\mathrm{A}}$ distance was found between the Yanbian and Nanyang breeds $(0.558)$, which is consistent with their geographical localization (Fig. 1). The Bohai breed is the only Chinese bovine breed, which has a black coat and thus it differs from other Chinese bovine breeds, which are yellow or red. The Bohai breed is positioned close to the Yanbian breed as shown by PCA and by their geographic distributions, but in the phylogenetic tree, it is found close to the Nanyang and Jiaxian breeds (Fig. 3).

Genetic and archeological evidence supports at least two domestication events for cattle from different wild progenitors. The aurochs types B. taurus, also termed taurine cattle, are postulated to have originated in the Near East and Africa, while B. indicus, or zebu, have arisen in India and Africa [10].

The earliest domestic cattle known in North China were the progenies of the Longhorn of B. taurus from Western Europe, which were distinguished from bachryseros and Bos primigenius taurus, and appeared with the introgression of Mongolian into the huge and extensive area to the north of China $[6,7,15]$. These breeds gradually adapted to the local environmental conditions and expanded southward but the Qinling Mountains and the temperature and weather conditions constituted natural barriers to their expansion. Meanwhile, the humped zebu inhabited the areas of the Yangtze and Zhujiang valleys and might have originated from the Bibos genus, such as the zebu, Bos bateng, and even Bos gaurus, which were also the progenitors of the zebu in Southeastern Asia [6,7,17]. The cattle breeds localized in the central parts of China and detouring the Qinling Mountains are situated at a cross-point and thus the analysis of their origin, domestication, and migration is much more complicated.

\section{ACKNOWLEDGEMENTS}

We thank Ms Helene Hayes for her kind help in editing the language and also thank the detailed comments and advice from the reviewers. We are also grateful to Dr. Minqiang Wang (Yantai University, China) and Mr. Xiaohong Lan 
(the Director of Shaanxi Qinchuan Cattle Farm, China) for their generous help in sample collection. This work was supported by the National Natural Science Foundation of China (30471238, 30070551), the National High Technology Research and Development Program of China (863 Program) (No. 2006AA10Z197), National Key Technology R\&D Program (No. 2006BAD01A10-5), Innovative Foundation of Outstanding Talent from Henan Province (No. 0521001900), Sustaining Program for Topnotch Persons of Northwest A\&F University (No. 01140101), Natural Science Foundation of Xuzhou Normal University (No. 2003XY234), and Program for New Century Excellent Talents in University of 2007 (NCET).

\section{REFERENCES}

[1] Barker J.S.F., A global protocol for determining genetic distances among domestic livestock breeds, in: Proceedings of the 5th World Congress on Genetics Applied to Livestock Production, Guelph and Ontario, Canada, 1994, pp. 501-508.

[2] Botstein D., White R.L., Skolnick M., Davis R.W., Construction of a genetic linkage map in human using restriction fragment length polymorphisms, Am. J. Hum. Genet. 32 (1980) 314-331.

[3] Bradley D.G., Loftus R.T., Cunningham P., MacHugh D.E., Genetics and domestic cattle origins, Evol. Anthropol. 6 (1998) 79-86.

[4] Cavalli-Sforza L.L., Menozzi P., Piazza A., The history and geography of human genes, Princeton University Press, Princeton, NJ, 1994.

[5] Chen H., Strategies of selection and breeding for the beef performance in Qinchuan cattle, J. Yellow Cattle Sci. 2 (2002) 1-4 (in Chinese with English abstract).

[6] Chen Y.C., Cao H.H., Diversity of Chinese yellow cattle breeds and their conservation, Chin. Biodivers. 9 (2001) 275-283 (in Chinese with English abstract).

[7] Chen Y.C., Wang Y.Y., Cao H.H., Zhang Y., Characteristics of Chinese yellow cattle ecospecies and their course of utilization, China Agriculture Press, Beijing, China, 1990 (in Chinese).

[8] Lei C., Chen H., Hu S., Study on the Y chromosome polymorphisms and origination and classification of Chinese cattle breeds, Acta Agriculturae Boreali occidentalis Sinica 4 (2000) 43-47 (in Chinese with English abstract).

[9] Lei C.Z., Chen H., Zhang H.C., Cai X., Liu R.Y., Luo L.Y., Wang C.F., Zhang W., Ge Q.L., Zhang R.F., Lan X.Y., Sun W.B., Origin and phylogeographical structure of Chinese cattle, Anim. Genet. 37 (2006) 579-582.

[10] Loftus R.T., MacHugh D.E., Bradley D.G., Sharp P.M., Cunningham E.P., Evidence for two independent domestications of cattle, Proc. Natl. Acad. Sci. USA 91 (1994) 2757-2761.

[11] McHugh D.E., Loftus R.T., Bradley D.G., Sharp M., Cunningham E.P., Microsatellite DNA variation within and among European cattle breeds, Proc. R. Soc. Lond. Ser. B 256 (1994) 25-31. 
[12] Nei M., Tajima F., Tateno Y., Accuracy of estimated phylogenetic trees from molecular data, J. Mol. Evol. 19 (1983) 153-170.

[13] Ota T., DISPAN: genetic distance and phylogenetic analysis, Penn. State University, University Park, PA, 1993.

[14] Park S.D.E., Trypanotolerance in West African cattle and the population genetic effects of selection, Ph.D. thesis, University of Dublin, 2001.

[15] Payne W.J.A., Tropical cattle: origins, breeds and breeding policy, Blackwell Science, Oxford, 1995.

[16] Qiu H., Qing Z.R., Chen Y.C., Wang A.D., Bovine breeds in China, Shanghai Scientific and Technical Press, Shanghai, China, 1988 (in Chinese).

[17] Ron M., Blanc Y., Band M., Ezra E., Weller J.I., Misidentification rate in Israeli dairy cattle population and its implications for genetic improvement, J. Dairy Sci. 79 (1996) 676-681.

[18] Saitou N., Nei M., The neighbor-joining method: a new method for reconstructing phylogenetic trees, Mol. Biol. Evol. 4 (1987) 406-425.

[19] Sambrook J., Russell D.W., Molecular cloning: a laboratory manual, 2nd edn., Cold Spring Harbor Laboratory Press, Beijing, 1992.

[20] Shan X., Zhang Y., Ning L.I., Effects of several microsatellite DNA loci on milk production in dairy cattle, Acta Genet. Sinica 5 (2002) 430-433 (in Chinese with English abstract).

[21] Takezaki N., Nei M., Genetic distances and reconstruction of phylogenetic tree from microsatellite DNA, Genetics 144 (1996) 389-399.

[22] Tamura K., Dudley J., Nei M., Kumar S., MEGA4: molecular evolutionary genetics analysis (MEGA) software version 4.0, Mol. Biol. Evol. 24 (2007) $1596-1599$.

[23] Tautz D., Notes on the definition and nomenclature of tandemly repetitive DNA sequences, in: Pena S.D.J., Chakraborty R., Epplen J.T., Jeffreys A.J. (Eds.), DNA Fingerprint: State of the Science, Birkäuser Verlag, Basel, 1993, p. 21.

[24] Wang Y., Cao H., Pang Z., Study on the blood polymorphisms of Chinese yellow cattle breeds and their genetic relationships, in: Ecological Characteristics and Utilization Directions, China Agriculture Press, Beijing, 1990 (in Chinese with English abstract).

[25] Weir B.S., Cockerham C.C., Estimating F statistics for the analysis of population structure, Evolution 38 (1984) 1358-1370.

[26] Yan L., Zhang D., Effects of sample size on various genetic diversity measures in population genetic study with microsatellite DNA markers, Acta Zool. Sinica 2 (2004) 279-290 (in Chinese with English abstract).

[27] Zhang Y., Several problems on the structure of Chinese animal production and beef industry, J. Yellow Cattle 2 (2003) 4-8 (in Chinese with English abstract). 